\title{
aniki
}

Revista Portuguesa da Imagem em Movimento

Portuguese Journal of the Moving Image

\section{Retrospecto sobre Andrea Tonacci: o já visto e o jamais visto Vitor Zan ${ }^{1}$}

Ciclo “Andrea Tonacci: L’intégrale” (Festival Cinéma du réel, Paris, 2017).

Só há imagem se houver suficientemente do outro para que um quiproquó ainda seja possível

Serge Daney

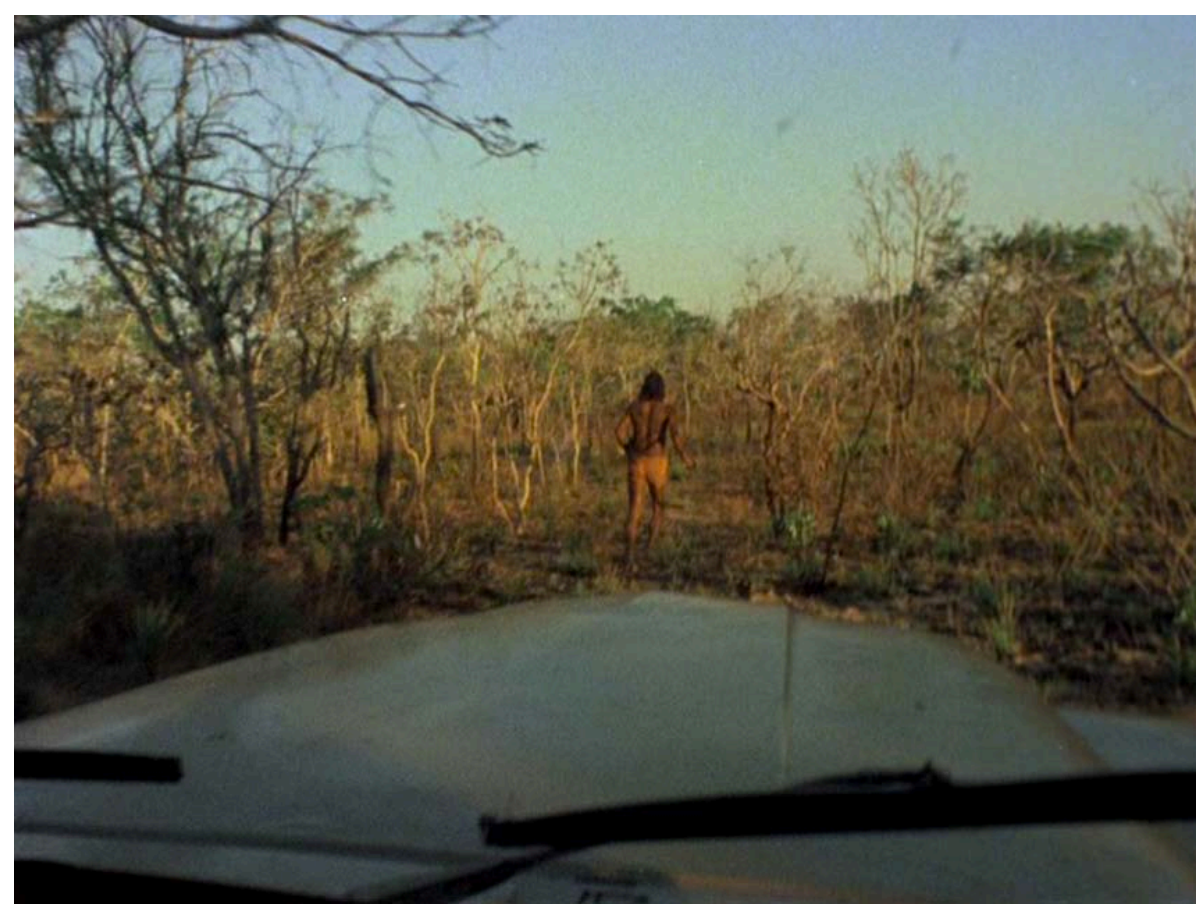

Imagem 1: Conversas no Maranhão (Andrea Tonacci, 1983) | ( Andrea Tonacci

No início da primavera de 2017, a 39a edição do festival de documentário Cinéma du Réel acolheu, em Paris, a primeira retrospectiva internacional de Andrea Tonacci, contando com a programação mais completa já realizada acerca da obra do cineasta ítalo-brasileiro, falecido em dezembro de 2016. Afora essa retrospectiva, o cinema brasileiro esteve representado por dois longas-metragens em competição: No intenso agora (de João Moreira

\footnotetext{
${ }^{1}$ Universidade Sorbonne Nouvelle - Paris 3, Département Cinéma et Audiovisuel, IRCAV, 75231, Paris, França.
} 
Salles) e Martírio (de Vincent Carelli, Tatiana Almeida e Ernesto de Carvalho), aos quais se soma, no bojo da lusofonia, Luz Obscura, da cineasta portuguesa Susana de Sousa Dias.

Com sua concepção felizmente impura do documentário, o Cinéma du Réel se fez tabernáculo propício para difundir a filmografia de Tonacci, que, a despeito de estar permanentemente em pé de guerra com o real, se ampara no experimental, na ficção, no documentário e no ensaio, sem se enquadrar plenamente em nenhum deles.

Além de retomar clássicos da carreira de Tonacci (praticamente desconhecidos no contexto francês), como Bang bang (1970) e Serras da Desordem (2006), a programação concebida por Patrícia Mourão e Gustavo Beck exibiu obras raras e inéditas, como o intrigante Jouez encore, payez encore (1974), que subsiste graças aos cuidados de Paulo Emílio Sales Gomes e que nunca havia sido exibido fora do Brasil. Já o riquíssimo material bruto do que seria o terceiro episódio de Os Arara, em que estão registrados os primeiros contatos com os índios Arara, nunca havia sido projetado publicamente $^{2}$. Ainda na esteira do ineditismo, gravações até então inexploradas feitas por Andrea Tonacci entre 1978 e 1980 com lideranças indígenas em diversos países das Américas deram ensejo à série Struggle to be heard: voices of indigenous activists.

Se pensarmos, com Pasolini, que é "absolutamente necessário morrer, porque, enquanto estamos vivos, falta-nos sentido" (Pasolini 1982, 196), já que, antes do corte final, a montagem de nossas vidas permanece em aberto e as ações futuras podem vir a alterar a expressão do todo, concluiremos que o momento postmortem é oportuno para o gesto retrospectivo. Uma vez concluída, definitiva, a obra, ou a vida, poderá enfim ser observada em seu conjunto. Somente então sua densidade será estimada com alguma precisão, seus aspectos mais relevantes apontados com maior segurança. Com efeito, esta retrospectiva proporcionou um novo tipo de imersão no universo tonacciano, deixando transparecer, aos olhos de admiradores, colegas, parentes e espectadores em geral, as feições de uma intensa aventura a um só tempo estética e existencial.

A inestimável perda de Andrea Tonacci não foi, contudo, a motivação dos curadores Patrícia Mourão e Gustavo Beck, que desde 2015 tentavam cunhar o evento em diferentes festivais internacionais e puderam, inclusive, contar com a participação ativa do cineasta na elaboração da programação. Além de contribuir para a concepção das sessões, Tonacci forneceu legendas desconhecidas (Conversas no Maranhão) e disponibilizou registros até então incógnitos ao público (Struggle to be heard).

\footnotetext{
${ }^{2}$ Exceção feita a uma projeção destinada a pesquisadores durante o encontro da Sociedade Brasileira de Estudos de Cinema e Audiovisual (SOCINE), em 2011.
} 
O afinco dos curadores foi irredutivelmente reforçado pela grande estima que o cineasta francês Sylvain George tem pela obra de Andrea Tonacci, o que ajudou a sensibilizar a direção do festival para sua contundência. Sylvain George, que havia escrito um belo artigo sobre sua obra (George, 2017), também dedicou a Tonacci seu último longa-metragem, que esteve em competição no mesmo festival: Paris est une fête : un film en 18 vagues.

Engajados em fomentar reflexões acerca da obra de Tonacci, os programadores organizaram um debate (protagonizado por Dario Marchiori, Naara Fontinele e Sylvain George) e convidaram críticos, pesquisadores e colegas de trabalho de Tonacci para apresentar as projeções. Dentre a profusão de ideias e interpretações que irrigaram a retrospectiva, três delas destacaram-se pela recorrência com que surgiram, observadas por pontos de vista diversos.

A primeira (frisada, por exemplo, por Sylvain George e Victor Guimarães) detecta na filmografia de Tonacci uma série de atributos que podem ser reagrupados sob a égide da desordem. Essa dimensão já se encontrava no caráter arbitrário que Olho por Olho (1965) e Bang Bang (1970) compartilham com outros filmes do cinema marginal, destilando em sua crítica acerba trajetórias errantes em grandes centros urbanos. Tal senso de errância faz eco nas produções mais tardias de Tonacci, seja nas atribulações da trajetória de Carapiru, em Serras da Desordem, seja na confluência de tempos e espaços que se confundem na estrutura disjuntiva de Já visto jamais visto (2013).

Consciente da complexidade das histórias e indivíduos, o cinema de Tonacci se recusa a domesticá-los em narrativas lineares, teleológicas, que respondam ao princípio classicista de causa e efeito. Assim, percalços, vicissitudes e mistérios não apenas são bem-vindos como se imprimem nas especificidades cinematográficas, dando origem a montagens fragmentárias, sobreposições visuais, personagens matizados e, em suma, a projetos que, embora concluídos, mantêm-se abertos, como processos inacabados, rústicos, guardando fissuras e deixando suspenso um sem-número de indagações.

O segundo eixo concerne à descentralização antropológica implicada na filmografia de Tonacci, promovida por seu profundo interesse pela alteridade, particularmente aquela referente à relação com povos ameríndios. Nos anos 1970, seu projeto Interpovos foi pioneiro na tentativa de colocar a recém-chegada tecnologia videográfica a serviço de povos indígenas, visando criar interações intertribais através do vídeo. Tonacci almejava dar voz ao outro, emancipá-lo da condição de objeto para torná-lo agente do discurso, promovendo o registro e a circulação de vídeos entre os diversos povos ameríndios. Tratava-se, por um lado, de um meio de contribuir para as reivindicações indígenas, como se nota na 
sequência marcante de Conversas no Maranhão (1983) em que é dada aos líderes dos índios Canela a possibilidade de registrar seu protesto acerca da demarcação de seu território. Por outro lado, Tonacci via um potencial introspectivo em sua aproximação do outro, pois olhar para o outro podia permitir enxergar a si mesmo por novas perspectivas, contaminadas por pontos de vista que lhe eram alheios.

Se o projeto se deparou com limitações intrínsecas a suas intenções e não chegou a se desenvolver tal como o cineasta havia idealizado, seu ímpeto gerou filmes de importância incontroversa, como Conversas no Maranhão e Os Arara, filmados entre 1978 e 1983. Desse mesmo impulso provêm os arquivos que compõem Struggle to be heard, inicialmente intitulado A Visão dos Vencidos, em que Tonacci confirma sua grande qualidade de escuta. A alteração do título foi feita a pedido de uma das lideranças indígenas que presta depoimento, o Cherokee Jimmie Durham, que incomodou-se com o termo "vencido" e preferiu pensar-se como aquele cuja luta deve ser ouvida. Tonacci acatou de bom grado a sugestão de Durham, reforçando sua recetividade.

Em um contexto de efervescência dos movimentos indígenas, líderes indígenas da América do Norte e do Sul declaram que sua principal batalha é pelo direito à terra e que o meio mais eficiente para obtê-lo reside na organização e na união. Tais discursos, que permaneceram ocultos por décadas, tendem a referendar (do ponto de vista indígena) a pertinência da iniciativa de Tonacci, uma vez que sua intenção era justamente criar maior coesão entre os diferentes povos e que, a respeito do território, ele já havia contribuído, à sua maneira, em Conversas no Maranhão, com índios que lutavam pela demarcação de suas terras.

A empreitada de Tonacci junto a povos indígenas inspirou diretamente Vincent Carelli, idealizador do projeto Vídeo nas Aldeias, que se dedica há décadas à formação de cineastas indígenas. Esse mesmo Vincent Carelli participou da retrospectiva, tendo feito, inclusive, uma declaração heurística que pode servir de transição para o terceiro e último tópico aqui sintetizado: "Eu não sou um cineasta, afirmou Carelli no debate, sou um militante que faz filmes. O Andrea estava mais preocupado com o cinema." Ele é certeiro ao enfatizar a importância do cinema para Tonacci, cujo interesse pelo outro, pelos contextos políticos em que esteve inserido, e até mesmo por si próprio, se manifesta por meios próprios ao cinema e implica em ponderações sobre esses meios, o que traz a seus filmes, de forma mais ou menos explícita, uma dimensão reflexiva.

A evidenciação, no interior da cena, da câmera cinematográfica e de outros dispositivos análogos aos do cinema é uma das formas como essa reflexividade se manifesta. Em Olho por Olho, um bando de jovens organiza uma cena de espancamento e convida um colega que tem um aparelho fotográfico para registrar o 
episódio. Em Blablablá, a demagogia política é assimilada à linguagem televisiva produzida em estúdio, alheia ao fervor das ruas. Na célebre sequência de Bang Bang em que o homem-gorila está a se barbear, a câmera se duplica não somente por sua presença dentro da cena, mas também por aparecer refletida em um espelho.

Dario Marchiori destacou o fato de que a relação de Tonacci com o outro também se elaborou em termos cinematográficos, desdobrando-se a partir do ouvir e do ver: dar voz ao outro, ouvi-lo, elaborar um lugar de fala e um lugar de escuta que leve em conta a situação de quem filma e de quem é filmado, como em Conversas no Maranhão ou em Struggle to be heard: voices of indigenous activists, cujo título já traz os tópicos da audição e das vozes. Quanto à visão, que estava no título $A$ visão dos vencidos, o que está em jogo não é o prazer escopofílico de olhar o outro, mas o esforço de aproximar-se de seu ponto de vista (inclusive para rever a si próprio). Por isso, durante o debate, Sylvain George tendeu a interpretar a reiteração da câmera dentro da cena menos como a busca de efeitos de distanciamento do que como a evidenciação de um exercício de perspectivismo.

Além disso, mantendo a discrição que lhe era própria, Tonacci deixa-se ver (enquanto sujeito e enquanto cineasta) em algumas instâncias de seus filmes, talvez sugerindo aos espectadores a viagem íntima envolvida em seu processo de criação. O momento mais emblemático dessa faceta da reflexividade vem à tona na sequência final de Serras da Desordem, em que o fim se conecta ao princípio e o filme expõe sua gênese no encontro de Carapiru com Tonacci, que é também a relação de um cineasta que dá instruções a seu protagonista, ou ainda o tête-à-tête entre um homem branco e um índio Awá-Guajá. Um a partir do outro, e a relação entre eles através do cinema.

Se em um dos episódios de Struggle to be heard o cineasta diz seu nome a uma criança, em Jouez encore, payez encore é Antônio Pitanga que encerra o filme, dirigindo-se para a câmera e dizendo "Andreeea," como bem notaram Luciana Bermudes e Ismail Xavier $(2012,31)$. Tais aparições lampejantes são relativamente pequenas comparadas à presença virtual do cineasta, que pode-se pressentir no antecampo. Tonacci é o seu próprio operador de câmera, um cineasta filmeur, como alegaram Tatiana Monassa e Naara Fontinele. Em alguns momentos, tem-se a impressão de que a câmera funciona como uma extensão de seu corpo, participando de uma economia com o mundo, o que faz com que sua forma de estabelecer relações, seu "rigor ético," nas palavras de Naara Fontinele, transpareça nos filmes, em particular na interação entre sujeitos filmados e sujeito que filma. Até mesmo em seu filme mais auto-biográfico, Já visto jamais visto, o cineasta se deixa ver mais por sua relação com aqueles que amava do que colocando-se em cena propriamente, ainda que 
apareça diversas vezes, inclusive portando a câmera, refletido em superfícies espelhadas.

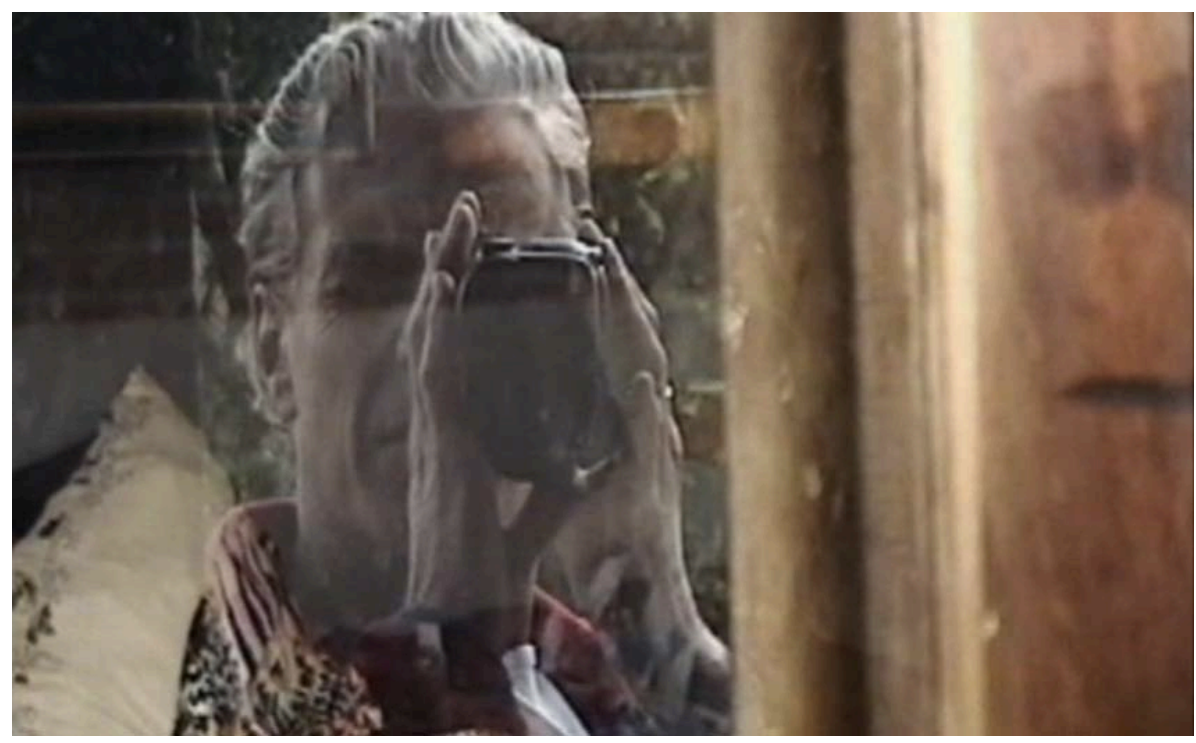

Imagem 2: Já visto jamais visto (Andrea Tonacci, 2013) | (c)Andrea Tonacci

A retrospectiva se encerrou, por fim, com a participação calorosa de Cristina Amaral, montadora e companheira de Andrea Tonacci, e Daniel Tonacci, filho do cineasta, cujas palavras afetuosas estão além desta resenha.

\section{BIBLIOGRAFIA}

Bermudes, Luciana e Ismail Xavier. 2012. "O teatro do mundo, de Calderón de la Barca, a máquina-olho, de Victor Garcia, e a câmera lúcida, de Andrea Tonacci”. Devires, v.9, n. 2, jul-dez: 16-33.

Daney, Serge, 1997. Devant la recrudescence des vols de sac à mains, cinéma, télévision, information (1988-1991). Aléas, Lyon.

George, Sylvain. 2017. "Andrea Tonacci, le cinéma du désordre et de l'infini”. La Furia Umana, 30. Disponível em http://www.lafuriaumana.it/index.php/63-lfu-30/668sylvain-george-andrea-tonacci-le-cinema-du-desordre-et-de-linfini

Pasolini, Pier Paolo. 1982. "Observações sobre o plano sequência”. In Empirismo Herege, 193-196. Lisboa: Assírio \& Alvim. 


\section{FILMOGRAFIA}

Olho por Olho. [curta-metragem] Dir. Andrea Tonacci. Brasil, 1965, $18 \mathrm{mins}$.

Blablablá. [curta-metragem] Dir. Andrea Tonacci. Brasil, 1967, 30mins.

Bang bang. [longa-metragem] Dir. Andrea Tonacci. Brasil, 1970, 90mins.

Jouez encore, payez encore. [longa-metragem] Dir. Andrea Tonacci. Brasil, 1974, 120mins.

Os Arara I, [longa-metragem] Dir. Andrea Tonacci. Brasil, 1980, $60 \mathrm{mins}$.

Os Arara II, [longa-metragem] Dir. Andrea Tonacci. Brasil, 1981, $60 \mathrm{mins}$.

Conversas no Maranhão. [longa-metragem] Dir. Andrea Tonacci. Brasil, 1983, 120mins.

Serras da Desordem. [longa-metragem] Dir. Andrea Tonacci. Brasil, 2006, 135mins.

Já visto jamais visto. [média-metragem] Dir. Andrea Tonacci. Brasil, 2013, 54mins. 